Indexaciones: Repositorio de Revistas UCR, DIALNET, Latindex, REDALYC Directorio y recolector de recursos digitales del Ministerio de Cultura de España, Directory of Open Access Journals. Diálogos Revista Electrónica de Historia ISSN 1409-469X. Número especial 2008. Dirección web: http://historia.fcs.ucr.ac.cr/dialogos.htm

\section{Perfil social de las actoras de las ventas de los mercados y de los espacios públicos en El Salvador a través de La Tribuna (1944-1948)}

\section{Claudia Ponce Prud' homme}

Residencial Miraflores, Poligono y Senda "A", No. 2. Soyapango, El Salvador

(503) 2291_1581

ponceclaudiasv hotmail.com

Lic. Historia: Universidad Tecnológica de El Salvador Lic. Relaciones Internacionales: Universidad de El Salvador 


\section{Perfil social de las actoras de las ventas de los mercados y de los espacios públicos en El Salvador a través de La Tribuna (1944-1948)}

\section{Un nuevo abordaje de las prácticas de ventas en los espacios públicos}

La idea surgió al enterarse del proyecto lanzado a partir del 2002 por el geógrafo francés, Jérôme Monnet $^{1}$, quien, proponía estudiar las "ventas ambulantes" desde los "vendedores ambulantes", sus prácticas de ocupación del espacio y sobre todo su movilidad, no sólo desde las preocupaciones de los poderes públicos y empresariales o retomando un enfoque económico que planteaba estas prácticas alrededor del debate sobre la informalidad y el dinamismo micro-empresarial. Este planteamiento novedoso de Monnet, llama la atención por la posibilidad de estudiar la temática más allá de sistemas de explicación y de conceptos que opacaban a las vendedoras como actoras sociales.

Jérôme Monnet formula la hipótesis de que una parte de las actividades comerciales en los espacios públicos se ha desarrollado con prácticas móviles de consumo de parte de los compradores, es decir, es una explicación de índole cultural que permite entender las prácticas de ventas en los espacios públicos de tránsito en el marco de la metropolización actual².

El planteamiento del "ambulantaje" se ha elaborado desde la geografía cultural alrededor de la cuestión del comercio y del consumo33 , éste despertó la atención por su capacidad a renovar el 1 En aquel entonces director del Centro de Estudios Mexicanos y Centroamericanos.

2 Ver Jérôme Monnet, Cruces comerciales: ambulantaje y servicios a la movilidad en la ciudad de México. (CD) "Comercio y movilidades urbanas en tiempos de metropolización". CEMCA, Universidad Autónoma Metropolitana (Iztapalapa) y Universidad Iberoameriacana, México D.F., 11-13 de julio de 2005.

3 Esta propuesta geográfica se articula muy bien con el cuestionamiento historiográfico 
cuestionamiento historiográfico, más interesado por el comercio capitalista a nivel nacional.

\section{Pensar las prácticas “informales” antes de la “informalidad”.}

El abordaje propuesto por el "ambulantaje" seduce, sobre todo por las posibilidades que abre a la investigación histórica. Por eso, mientras que el uso de la noción de "informalidad", muy ocupado por los sociólogos, psicólogos sociales y economistas, es muy problemático para los historiadores, el ángulo creado por el "ambulantaje" brinda una oportunidad de escribir una explicación diacrónica, más allá de los últimos treinta y cinco años.

Rafael Menjívar Larín insistía que la informalidad era sobre todo un proceso laboral más que productivo, es decir un fenómeno de generación de empleo, en el cual se pueden analizar dos momentos de existencia de la capacidad laboral: su intercambio (o sea, el mercado de trabajo) y su reproducción (o sea, el hogar) ${ }^{4}$. Por lo cual, se recalca la naturaleza heterogénea, característica fundamental de este fenómeno y por ende la necesidad de una tipología. En esta línea, logra identificar tres tipos de informalidad que le son útiles a su estudio: las microempresas dinámicas caracterizadas por su tendencia al incremento de la relación capital/trabajo y con capacidad acumulativa; las situaciones a caballo entre la dinámica acumulativa y la reproducción simple de subsistencia y por último las lógicas de subsistencia de reproducción simple ${ }^{5}$.

Respecto a El Salvador, el economista Carlos Briones afirma que el primer intento de caracterización del sector informal urbano en El Salvador se encuentra en un trabajo realizado por PREALC (1975) en el año de 1974 con el objetivo de evaluar la situación y perspectivas contemporáneo alrededor de la historia del consumo, que varios historiadores centroamericanos han compartido a partir de un proyecto lanzado en la Universidad de Costa Rica y presentado en el VIII Congreso Centroamericano de Historia, La Antigua Guatemala, 10-14 de julio de 2006.

4 Rafael Menjivar Larín y Juan Pablo Pérez Sáinz, Ni héroes ni villanas: Género e informalidad urbana en Centroamérica. San José: FLACSO-Costa Rica, 1993, p. 16.

$5 \quad$ Ibídem, pp. 16-17. 
del empleo en El Salvador. (...) En este trabajo se hace énfasis en las características socioeconómicas del trabajador informal debido a que la fuente de datos es una encuesta demográfica y de mano de obra realizada en el Área Metropolitana de San Salvador con el objetivo de evaluar la situación ocupacional en el principal polo urbano del pais 6 .

De esta innovación en la sociología, la economía y la psicología social, los "pobres urbanos" se habían vuelto "informales marginales", sin provocar grandes problemas epistemológicos. Sin embargo, desde el análisis histórico, esa categoría era de uso muy difícil. Por un nuevo ángulo institucional, herramienta de evaluación de un proyecto político-económico, los mismos trabajadores precarios de antes de los años 1950 se convertían en "informales" a partir de estos años. Las ciencias sociales habían fabricado una nueva categoría social para abarcar al grupo de trabajadores que tenían que beneficiarse del proceso modernizador basado en la industrialización y en la protección social. Desde entonces, bien los trabajadores se beneficiaban y eran formales, bien se ubicaban en la informalidad. Si esta categorías socio-económica era aplicable a partir de los años 1950, uno puede preguntarse, ¿tiene sentido en el caso de los periodos anteriores? Según este estudio, no.

En El Salvador, justo antes de 1948, la industria ocupaba menos del 7\% del empleo urbano, y la protección social era solo un proyecto en debate. Más aún, se considera que, fuera de unos grupos sociales muy reducidos, la informalidad era lo más general, a nivel laboral, residencial y educativo, para más de un 70\% de la población salvadoreña. ¿Qué hacer de esa noción de "informalidad" si abarca un grupo tan amplio, tan diverso respecto a sus prácticas sociales y tan $6 \quad$ Carlos Briones, "Los análisis realizados sobre el sector informal urbano en El Salvador: una evaluación general”, en R. Menjívar Larín y Pérez Sáinz (compiladores), Informalidad Urbana en Centroamérica. Evidencias e Interrogantes. Guatemala: FLACSO-Fundación Fiedrich Ebert, 1989, p. 60. 
polimorfo? Quizá haya que fabricar una noción más precisa y apegada a las dinámicas sociales de la época. De esta manera, se sostiene la hipótesis que el perfil social de las vendedoras de los mercados y de los espacios públicos de tránsito entre 1944-1948 pertenecen a un marco de prácticas "informales", antes que a la "informalidad" entendida en el sentido actual.

La elección de los años 1944-1948, para realizar el estudio, se justifica por la intención de esta tesis sobre las vendedoras de los mercados y de las calles, para ser un primer elemento de diálogo con las nociones, de "informalidad" en El Salvador, usadas desde hace más de treinta años, y del "ambulantaje", usada hace pocos años. Por esta razón, se ha escogido el período de los años cuarenta para, en primer lugar, dialogar con los numerosos estudios posteriores, realizados en El Salvador por sociólogos y economistas sobre el tema de la "informalidad"; en segundo lugar, cuestionar el "inicio" y por ende la "génesis" del fenómeno en los años cincuenta ${ }^{7}$. Este estudio no busca extraviarse en la búsqueda del origen, sino cuestionar las explicaciones macroeconómicas y sobre todo el apartado de "los antecedentes históricos", en muchos de estos estudios.

\section{Historia social: una metodología}

El interés de este estudio es reconstruir el perfil social de las vendedoras de los mercados y de las calles en San Salvador a partir de representaciones seleccionadas de manera sistemática en el periódico La Tribuna, publicado en San Salvador. Tanto los sujetos y objetos de estudio como la metodología utilizada se fundamentan en los planteamientos de la historia social que se vienen desarrollando desde hace más de quince años en Europa. En este apartado, se van a presentar los lineamientos de la investigación en el marco historiográfico.

Identificación del o de los perfiles sociales de las vendedoras de los mercados y de

$7 \quad$ Ver el estudio de José R. López Mira, Dinámica estructural del sector informal en El Salvador. San Salvador: DYGESTIC, 2004. 


\section{las calles en San Salvador}

A partir de las representaciones de la fuente primaria, se han planteado preguntas básicas para discernir el o los perfiles sociales de los actores y actoras de las ventas de los mercados y de los espacios públicos en San Salvador: la procedencia, su nivel económico, la edad, el estado civil y la residencia. Desde el inicio, se ha buscado identificar a las personas que practicaban las ventas en las calles y en los mercados, ya que vale la pena señalar que no consideramos a los trabajadores en las calles como marginales, pues esta categoría sume por definición a estos actores en una posición de exclusión dentro de un sistema social. Por el contrario, se ha encontrado que estos actores sociales participan en la vida cotidiana con las posibilidades que les brinda cada momento y cada espacio social, se adaptan a las circunstancias para lograr mínimas condiciones de sobrevivencia ${ }^{8}$.

En las categorías sociales usadas por los investigadores que estudiaron la primera mitad del siglo $\mathrm{XX}$, se observó la poca visibilidad de las vendedoras en los mercados y en las calles, fuera de las campesinas y de las pocas obreras de fábricas, las vendedoras cuando no eran campesinas, eran invisibles. De repente, aparecen en una frase, u otra, o en alguna foto, no más. No se distingue y ni siquiera se conoce si estaban incluidas, concientemente, en categorías macroscópicas como "las masas populares", "el proletariado", "los trabajadores". A partir de estas observaciones, se comparte la opinión de Bernard Lepetit cuando escribe: En lugar de cosificar a los grupos (estamentos, clases, ciudades, tribus, etc.) y de considerar como dado, en la base de una batería de criterios esenciales (una posición de linaje, una posición económica, etc.), la pertenencia de los individuos a estos grupos que los encierran y los definen, ahora las ciencias sociales

8 Mario Cruz Barbosa, "Trabajadores en las calles de la ciudad de México: Subsistencia y pobreza urbana al comenzar el siglo XX”. México D. F.: ponencia presentada en el Colegio de México, febrero de 2006. 
invierten la perspectiva9.

Este estudio retoma esta nueva perspectiva de las ciencias sociales, lo que implica partir de los sujetos y de sus prácticas a través de la fuente estudiada para construir un perfil o varios perfiles sociales que quizá permitan vislumbrar dinámicas sociales poco visibles hasta ahora. A esta escala, este estudio se inscribe en la historia social lanzada a finales de los años 1980, la cual "ya no se ancla en una crítica de los hábitos de la disciplina en nombre de las innovaciones de las ciencias sociales, sino en una crítica de los postulados de las propias ciencias sociales. El fundamento intelectual del salto está claro: la vuelta a una filosofía del sujeto que rechaza la fuerza de las determinaciones colectivas y los condicionamientos sociales y que pretende rehabilitar "la parte explícita y meditada de la acción"10.

\section{Pensar el trabajo femenino desde la historia de las mujeres}

La mayoría de personas que ejercían el oficio de las ventas ambulantes y de los mercados eran mujeres, tanto en los resultados de la fuente utilizada en este estudio, como en el "Catálogo de imágenes"11. Es por ello, que se incluye esta reflexión sobre el trabajo femenino desde la historia de las mujeres, pero vista como parte de la historia social.

En el balance publicado en 1997 sobre los aportes de la historia de la mujer y de género en América Latina, Virginia Mora Carvajal presenta el trabajo femenino, en especial el de las mujeres de los sectores populares como uno de los temas que presentan más dinamismo en la

$9 \quad$ Bernard Lepetit, "Histoire des pratiques, pratique de l'histoire” en Les formes de $l \square$ expérience: une autre histoire sociale, París: Albin Michel, 1995, p. 17.

10 Roger Chartier, "El mundo como representación”, en Historia Social, n 10, primavera-verano 1991, p. 164.

11 Olivier Prud'homme, Oscar Campos y Lorena Olmedo, Catálogo de imágenes sobre las ventas ambulantes entre 1890 y 1940. Ponencia inédita presentada en el coloquio: "Las ventas ambulantes en los espacios públicos de tránsito”, UCA, San Salvador, 3-6 de julio de 2006. 
historia de género ${ }^{12}$. Una mirada a la bibliografía en que se basa la investigadora revela que las obras citadas datan de los años 1980, ello despierta dudas sobre el seguimiento de ese dinamismo para los años 1990. Otro elemento que alimenta esta duda es que el balance propuesto, esta vez por Eugenia Rodríguez Sáenz, a escala de Centroamérica, no cita entre los temas más estudiados en la región el del trabajo femenino en los sectores populares. Esto puede explicar la ausencia casi total en Centroamérica de estudios históricos publicados recientemente. En este caso, sólo se ha encontrado un artículo de la misma Virginia M. Mora Carvajal, titulado "Los oficios femeninos urbanos en Costa Rica. 1864-1927"13.

La primera conclusión a la que llega la historia del trabajo femenino es a la invisibilidad de las mujeres en este campo, tanto en Centroamérica como en Europa. Las dos causas más destacadas y vinculadas son la ceguera estadística del Estado ${ }^{14}$ y las representaciones culturales que descartan o minusvaloran las actividades realizadas por mujeres que no tienen una relación con la maternidad y el hogar.

En el caso de El Salvador, en primer lugar, el Estado respaldaba sus categorías estadísticas en las representaciones socio-culturales producidas en el país y, por ende, consideraba que las mujeres no se debían salir del espacio doméstico, sino como ayudantes del jefe de hogar (padre, esposo...), es decir, no representaban actores reconocidos de la economía nacional. En segundo lugar, en los años cuarenta, el mundo asalariado, incluso en las ciudades, era una excepción en la economía salvadoreña, y aún más para las mujeres. Lo que significa que no sólo las mujeres,

12 Virginia Mora Carvajal, "Mujeres e historia en América Latina: En busca de una identidad de Género", en Entre silencios y voces. Género e historia en América Central (1750-1990). San José: Editorial de la Universidad de Costa Rica e INAMU, 2000, p. 8.

13 Virginia M. Mora Carvajal, "Los oficios femeninos urbanos en Costa Rica”, en Mesoamérica, n 27, junio de 1994, pp. 127-209.

14 Sylvie Schweitzer, Les femmes ont toujours travaillé: une histoire du travail des femmes au XIX et XXe siècles, Paris: Odile Jacob, 2002, pp. 77 y 79. 
sino la mayoría de los campesinos, quedaban fuera de las estadísticas.

No hay que olvidarse que para los años cuarenta las herramientas estadísticas eran incipientes en El Salvador, mucho más, por ejemplo, que en Costa Rica. Esto significa que la invisibilización no se limita a las mujeres sino a una gran parte de la población no asalariada de aquella época. Un segundo aspecto a considerar es que en los dos primeros censos de este país -1930 y 1950-, se eluden las actividades femeninas agrícolas y comerciales. Tercero, las memorias estatales, como el proyecto de creación del Seguro Social, entre 1944 y 1948, no toman en cuenta las actividades femeninas. Sin embargo, retomando a Michelle Perrot y a Sylvie Schweitzer ${ }^{15}$, obviamente las mujeres siempre trabajaron, y una parte no marginal de ellas ${ }^{16}$.

Este estudio considera que la práctica de la informalidad era generalizada entre 1944 y 1948, en lugar de considerar que estas mujeres pertenecían a una economía informal, se demuestra en este estudio que desde el Estado, la invisibilidad-informalidad-marginalización de estas mujeres era total, no sólo en cuanto a su práctica de subsistencia, es decir en el campo laboral y

15 "Retomo a la irónica pregunta que Michelle Perrot plantea sobre el trabajo: “¿Habría que recordarlo?: las mujeres siempre trabajaron (...)" Como en este trabajo, la historiadora dominicana Dora T. Dávila, cita esta frase de Michelle Perrot en su artículo sobre el papel que desempeñaron las mujeres en las actividades económicas en Santo Domingo durante la época colonial. Dora Teresa Dávila, "Mercaderes esenciales. Los comerciantes y las redes informales de la economía colonial en Santo Domingo", siglo XVIII, en Mujeres, Género e Historia: En América central durante los siglos XVIII, XIX y XX. San José: UNIFEM y Plumsock Mesoamerican Studies, 2002, p. 5. También, la historiadora Sylvie Swcheitzer publicó un libro sobre la historia del trabajo femenino en Francia con esta interrogante.

16 Como lo analiza Virginia Mora Carvajal en su artículo sobre Los oficios urbanos en Costa Rica, a partir de cuatro censos entre 1864 y 1927, (en el caso de El Salvador, el primer censo a escala nacional se hizo en 1930), los oficios más feminizados y con más empleos son las cocineras, las costureras, las lavanderas y las sirvientas; ocupaban cada oficio miles de mujeres. Por lo menos, un $96 \%$ de los cocineros registrados, de los 2,858 en 1864, y de los 3,127 en 1927, eran mujeres. Las costureras eran 5,232 en 1864, 2,129 en 1927; las lavanderas alcanzaron a ser 5,873 en 1892, y un $90 \%$ de los 2,561 sirvientes en 1883, eran mujeres. Sorprende que no se lea el oficio de las vendedoras de las calles y de los mercados entre los doce oficios urbanos registrados por Virginia Mora Carvajal a partir de los cuatro censos costarricenses entre 1864 y 1927, mientras que se podía leer la presencia de "comerciantes" entre los oficios urbanos. Parece ser otra evidencia de la invisibilidad de una actividad femenina, en este caso, la actividad que se va a estudiar en esta tesis. Virginia M. Mora Carvajal, Ob. Cit., p. 131. 
económico, sino también en el campo residencial o de la ocupación del espacio urbano y en el campo educativo ${ }^{17}$.

\section{Fuentes escritas sobre el comercio en los mercados y en las calles. Proceso de búsqueda y selección}

Al identificar el perfil social, se ha tenido que buscar fuentes apropiadas para alcanzar el objeto de estudio. Como no se han escrito libros de historia sobre este tema, sino solo tres libros de sociología y/o economía sobre "las informales"18, se debió seguir un recorrido largo para decidir sobre la fuente más apropiada, que finalmente fue el periódico La Tribuna.

La búsqueda se realizó en diferentes tipos de fuentes, como las estatales, municipales, literarias, fotográficas y periodísticas. Entre las fuentes estatales, el recorrido inició en la Colección Salvadoreña "Claudia Lars" de la Biblioteca Nacional, donde se encuentran los libros nacionales más antiguos, la mayoría editados entre 1885 y 1925, y en menor cantidad, entre 1925 y 1950. Otras fuentes revisadas fueron las series de Memorias de Labores de varios ministerios del Estado de El Salvador (Hacienda, Economía y Asistencia Pública) entre finales del siglo XIX y mediados del XX, pero en ninguna se encontró referencias al comercio urbano al detalle en los

17 La mayor parte de las mujeres trabajadoras parecen haber tenido un aprendizaje más bien de carácter informal en el seno del hogar, ligado más a valores y a conductas sociales que al desarrollo de habilidades especificas para el desempeño de ciertas labores. Ibídem, p. 132. Algunas mujeres coincidieron en que su falta de estudios y de preparación no les permitió otra forma de ganarse la vida. Aída Redondo y María Juárez, "Las vendedoras de los mercados y su consciencia feminista". Managua: X aniversario de ANICS: Agresión externa, sobrevivencia y democracia popular, ponencia dactilografiada, 1986, p. 14.

18 Carlos Briones, "Los análisis realizados sobre el sector informal urbano en El Salvador: una evaluación general”, en R. Menjívar Larín y J.P. Pérez Sáinz (compiladores), Informalidad Urbana en Centroamérica. Evidencias e Interrogantes. Op. Cit., Rafael Menjívar Larín y Juan Pablo Pérez Sáinz, Ni héroes ni villanas: Género e informalidad urbana en Centroamérica. San José: FLACSO-Costa Rica, 1993. Héctor Salazar, Las informales: Estudios sobre el sector informal urbano femenino en El Salvador. San Salvador: HECSAL, INCIDE-PRONAFORD, 1994. 
mercados y en las calles.

Asimismo, en el Archivo General de la Nación (A.G.N.), se hizo un sondeo en el "Fondo de Gobernación" entre 1890 y 1940. Se encontró un fondo reducido pero muy interesante: el "Fondo de Mercado". El catálogo organizado por los encargados del acervo presenta varias cajas: 1927, 1940-1941, 1948, 1953, 1967. La fuente es valiosa: se pueden encontrar cartas de las locatarias dirigidas al "Administrador del Mercado" e informes administrativos que tratan de traslados de local, renta del local, tensión entre las "vendedoras" (sic) y vigilantes del mercado, robo en el mercado y tren de aseo. Sin embargo, no se eligió este fondo por el desfase que presenta entre el tamaño reducido del fondo y la discontinuidad de la fuente que no cubrían los requisitos de una tesis de licenciatura, en función de la cual se situaba el estudio.

En las fuentes municipales, se indagaron cuatro dependencias de la Alcaldía de San Salvador: el Archivo Municipal de San Salvador, la oficina del Distrito Central, la Gerencia de los Mercados Municipales de San Salvador y la sede del Cuerpo de Agentes Municipales.

En el Archivo Municipal de San Salvador, se consultaron las actas municipales de la Alcaldía, producidas durante la primera mitad del siglo XX. De hecho, se hallaron debates sobre la administración de los mercados capitalinos, el papel de las calles y de los edificios públicos para realojar a las llamadas "vendedoras" y sobre las relaciones entre las locatarias de los mercados, las vendedoras de la calle y la administración municipal. Otra vez, si los datos son interesantes, resultan insuficientes para obtener una serie que posibilite la investigación.

Entre las fuentes literarias, varias obras de la primera mitad del siglo XX mencionan, incluso describen, las ventas en los mercados y/o en los espacios públicos de ciudades y pueblos de El Salvador. Las crónicas y novelas de Alberto Masferrer, y de Arturo Ambrogi son dos ejemplos 
concretos de que la literatura es una fuente valiosa para abordar este tema. Lastimosamente, estas fuentes sólo pueden ser complementarias. De hecho, no fue encontrada una obra literaria que se enfoque sobre un vendedor de la calle o del mercado. De igual manera que sobre las fuentes citadas anteriormente, no se puede hablar de una serie suficientemente amplia para constituir el corpus principal de fuentes de una tesis.

Finalmente, la búsqueda se situó en una fuente muy prolífica en el siglo XX, pero también de manejo delicado: los periódicos. Se realizó un sondeo en el campo periodístico de la primera mitad del siglo XX. Se consultaron, sobre todo, periódicos nacionales de los decenios 1920, 1930 y 1940, por tener una oferta informativa más amplia: El Diario de Hoy, La Prensa Gráfica, Diario de El Salvador, La Tribuna, Diario Latino. En varios de estos diarios, se localizó información sobre vendedores de los mercados y de los espacios públicos.

Al final de este recorrido muy enriquecedor, pero también bastante largo, a través de fuentes posibles para estudiar las ventas de los mercados y de las calles, se realizó la selección del corpus documental y se precisó el marco histórico y geográfico. Así, se optó por el diario La Tribuna, publicado entre julio de 1944 y diciembre de 1948, y se tomó la decisión de que los sujetos serían las vendedoras y vendedores de los mercados y de las calles de El Salvador. A través de sondeos, resultó ser una de las fuentes que tiene la frecuencia más alta de noticias sobre estas actoras de los mercados y de los espacios públicos, principalmente en San Salvador.

\section{Presentación de la fuente seleccionada: el periódico La Tribuna}

Es difícil caracterizar la línea editorial del diario, ya que se observó una gran inestabilidad de los directores, asimismo del perfil político de ellos y del grado de coacción estatal entre 1944 y 1948. Se distinguen cuatro momentos que marcaron bifurcaciones en la orientación política del 
periódico. El primer momento fue muy breve, solamente de cuatro meses pero, a la vez, muy determinante; inició el 18 de junio de 1944 y finalizó el 20 de octubre de 1944, se definió por el único momento de libertad de expresión. En es marco se fundó La Tribuna bajo la dirección de Pedro Geoffroy Rivas ${ }^{19}$, un intelectual que se manifestaba comprometido con las aspiraciones democráticas y de justicia social expresadas fuertemente en aquella época. Al parecer en este momento el periódico tenía las características internas y externas más favorables para producir noticias y artículos sobre "lo popular" y "lo social” y para que se enfocara en sujetos sociales como las vendedoras de los mercados y de las calles.

El segundo momento, fue marcado por continuar con la línea editorial iniciada por Pedro Geoffroy Rivas, es decir, hasta el $1^{\circ}$ de marzo de 1946, los dos directores que se sucedieron, se proponían participar en los debates políticos desde una postura favorable a los mecanismos democráticos y a una intervención pública más importante en el área social, cuando las relaciones con el Estado habían pasado repentinamente de la no intervención a la coacción sobre la prensa. Esto fue expresado abiertamente por La Tribuna durante la dirección de Pedro Geoffroy Rivas, después los presidentes de la República, Osmín Aguirre, primero, y el General Castaneda Castro, luego, consideraron las declaraciones de este tipo como una provocación y echaron mano de la censura. Si bien la intención del diario pareció seguir enfocada en la cuestión social e interesada por las vendedoras de San Salvador, las presiones del jefe de gobierno pudieron afectar la escritura de

19 En junio de 1944, Pedro Geoffroy Rivas regresaba de México donde se había graduado en Derecho. Tenía una experiencia política como militante del Partido Comunista y había escrito dos libros de poemas: Rumbo en 1934 y Canciones en el Viento, en 1936. Carlos Gregorio Flores, Biografias de escritores salvadoreños, San Salvador: Editorial Libertad, 1994, pp. 70-71. Esta pequeña biografía en aquel contexto de aspiraciones liberales y democráticas, después del Martinato, hacen pensar que al primer director de La Tribuna, los dueños de la "sociedad anónima" lo habían escogido por su libertad de tono y su postura política - ¿vanguardista?-, Pedro Geoffroy Rivas $\square$ continuando así su labor en pro de la causa revolucionaria (...)”. Julián de Cuscatlán, Historia del periodismo salvadoreño. San Salvador: Exposición continental del periodismo, 1960, p. 29. 
las noticias "sociales".

A partir de marzo de 1946, ocurrió una ruptura en la orientación del periódico. La llegada de Hugo

Lindo y su rechazo al comunismo marcó una postura más aceptable para el General Castaneda Castro. Una parte del equipo de redacción cambió y uno de los dueños del periódico se volvió el gerente del diario. El periódico se ajustaba al control estatal. Hugo Lindo, como su sucesor, y aún más, José Quetglas, que tuvo la dirección más larga del diario, defendieron una postura que creían auténtica, hasta crítica en ciertos momentos, pero que acataba las reglas de control a la libertad de expresión impuestas por el General Castaneda Castro. Ya no buscaban como en el primer año de La Tribuna la defensa del espacio de libertad de expresión total en el cual se fundó el diario. Definitivamente, este ajuste interno a la presión externa pudo provocar un cambio de escritura en ciertas noticias sociales que el General Castaneda Castro podía considerar como de índole política.

Los últimos cuatro meses de La Tribuna marcaron la culminación del control de Castaneda Castro sobre este diario. Al volverse el jefe de Estado el accionista mayoritario del periódico, el pequeño margen de libertad desapareció. Con los dos últimos directores, Alberto Rivas Bonilla y Francisco Espinosa, La Tribuna se transformó en una herramienta de difusión de los discursos del General Castaneda Castro.

\section{Perfil social de las actoras de las ventas: actividad dominada por mujeres, poco visibles}

Si entre 1944 y 1945, la economía salvadoreña padeció por la coyuntura internacional desfavorable, a partir de 1945 y hasta 1957-1958, es decir mucho más allá del final del periodo de estudio, esta misma economía creció rápidamente debido a la elevación de los precios mundiales del café. Después de la Segunda Guerra Mundial, el nuevo arranque de la economía occidental por la 
reanudación de los intercambios comerciales alimentó este periodo de bonanza en El Salvador. Héctor Dada Hirézi lo demuestra muy claramente: Los precios del café salvadoreño pasaron de un índice de 100 en 1945 (37.24/qq para el café salvadoreño), a 275 en 1950 (102.53/qq). Hacia 1950, el café representaba más del 80\% de las exportaciones. (...) A raiz, por ejemplo, de los continuos saldos favorables de la balanza de pagos, las reservas internacionales habian aumentado de 21 millones y medio de colones en 1941, a 156 millones de colones en junio de $1951^{20}$.

La economía salvadoreña de agro-exportación, era “dual”, es decir, dependía del mercado mundial y a la vez debía articularse con la economía de subsistencia que permitía alimentar no solo a la mano de obra necesaria para el desarrollo de la agro-exportación sino a toda la población, cualquiera fuera su rol económico ${ }^{21}$. Esto permite entender las explicaciones de Alexander Segovia sobre la precariedad generalizada que tenía que aceptar una gran parte del campesinado centroamericano: Debido a que dichos cultivos (de agro-exportación) se caracterizan por su estacionalidad en el uso de mano de obra, el mercado de trabajo salvadoreño (y centroamericano) ha registrado históricamente una marcada inestabilidad laboral. (...) El sistema agro-exportador requería anualmente cientos de miles de trabajadores migratorios para recolectar los cultivos de exportación durante el periodo de cosecha, pero no era capaz de garantizarles un salario para todo el año, por lo cual se apoyaba en la perpetuación del sistema de subsistencia campesina. En la medida en que la mayor parte de los costos de reproducción de esa fuerza de trabajo eran provistos por el trabajo impago de los miembros del grupo familiar campesinado que trabajaban en los minifundios, el sector agro-exportador podía ofrecer salarios mucho menores que los que 20 Dada Hirézi Héctor, La economía de El Salvador y la integración centroamericana 1945-1960. San Salvador: UCA Editores, 1987, p. 30.

21 En este sentido ver a: Víctor Bulmer Thomas, La economía política de Centroamérica desde 1920. San José: Banco Centroamericano de Integración Económica, 1989, p. 149. 
se habrían requerido para mantener a un trabajador asalariado durante todo el año ${ }^{22}$.

En este marco de una economía dual en la cual la agricultura de exportación alrededor del café se beneficiaba de precios muy favorables, se tiene que ubicar a las vendedoras de los mercados y de los espacios públicos de los pueblos y ciudades en El Salvador entre 1944 y 1948, sin desvincularlas del crecimiento poblacional y de la situación precaria generalizada en la ciudad y en el campo, que, debido al bajo nivel de ingresos y al desarrollo de transportes más rápidos, empujaba a la movilidad hacia la ciudad.

\section{La hiper-representatividad de las ventas y de las vendedoras de los mercados y de los espacios públicos en San Salvador}

Existe una clara hiper-representatividad de San Salvador durante todo el periodo de difusión de La Tribuna. La ciudad de San Salvador, es mencionada 228 veces, entre 368 noticias que abordan las ventas callejeras y de los mercados en todo el país. En segundo lugar, se observa a Santa Ana y a Usulután, y de manera más reducida, a Chalatenango y San Miguel, como las ciudades más mencionadas entre un total de 26, dependiendo del periodo.

Ya se había observado esa hiper-representatividad en el catálogo de 42 imágenes-fotos y grabados que procedían de 10 fuentes distintas, revistas, diarios y libros, entre 1890 y 1939, ya que, entre 12 ciudades y pueblos, San Salvador representaba un $40 \%$ de las imágenes encontradas ${ }^{23}$.

De acuerdo a los resultados, por una parte, se considera que esta hiper representatividad resulta de la fijación de los periodistas en San Salvador, debido a la ubicación de la sede del diario y a su interés por la capital. En buena medida, también, refleja la geografía de las ventas en El 22 Alexander Segovia, Transformación estructural y reforma económica en El Salvador. Guatemala: F. y G. Editores, 2002, p. 60.

23 Olivier Prud'homme, Oscar Campos y Lorena Olmedo, Ob. Cit. 
Salvador. Por otra parte, se observa que la distribución de las ventas, siempre céntricas -en los pueblos y ciudades- se distribuían entre los mercados y otro espacios públicos -calle, plaza y/o parque-, y que muchas veces, los periodistas relacionaban las vendedoras de las calles con las de los mercados, ya fuera por una razón urbanística, social y/o económica.

Esta presencia numerosa de mujeres vendedoras del mercado y de las calles tiene que ver con la aceleración y, por ende, el aumento de todos los tipos de flujos -diarios, estacionales y sin vuelta- hacia la capital, lo que provocó una densificación y una expansión de la ciudad, que para los años 1944-1948 ya tenía entre 15 y 20 años. Era un nuevo centro ${ }^{24}$.

La población urbana nacida en San Salvador vio llegar a emigrantes rurales y, en una menor proporción, a urbanos de ciudades secundarias nacidos fuera de la capital, y que probablemente representaron por lo menos un tercio de la población de la capital en los años 1940: Un problema que afecta seriamente a la capital y a las grandes poblaciones del país, es la escasez de la vivienda. Sencillamente: no hay casas en las ciudades. La causa, una de tantas, es la incesante inmigración de los pueblos. El entusiasmo por las ciudades está despoblando a las poblaciones pequeñas. En El Salvador hay pueblos que tienden a desaparecer: San Juan Opico, Ciudad Barrios, Alegría, San Alejo han visto el éxodo interminable de sus habitantes que buscan la vida en otras partes, generalmente la capital. Resultado: las poblaciones pequeñas se extinguen y la capital se congestiona ${ }^{25}$.

24 Al tiempo que se daba un proceso urbano inédito en la ciudad de San Salvador, de diferenciación horizontal profunda clasista del espacio urbano que habría de expresarse final y precisamente en esta década de los treinta, en las primeras expansiones urbanas del siglo XX, dando lugar a la constitución de un nuevo "centro" de la ciudad de San Salvador, compuesto ahora, ya no sólo por la vieja traza española, sino también por sus muy viejos barrios coloniales en los que empezaría la subdivisión de las construcciones que los propietarios empezaron a dejar abandonadas en alquiler a los trabajadores y pobres sin trabajo para convertirse en mesones, emigrando ellos al Poniente de San Salvador. Flora Leticia I. Salazar Ledesma, Memorias de la antigua ciudad de San Salvador: Historia del barrio de La Concepción, 1553-1926. México D. F.: Instituto Nacional de Antropología e Historia, 2004, p. 101.

25 Sin autor, "Crónicas de El Salvador”, en ECA, julio-agosto de 1946, p. 74. 
En este mundo rural dominante, los flujos masivos e intensos, los conformaban los campesinos ocupados permanentemente en la agricultura de subsistencia o estacionalmente entre regiones de cultivo de exportación y de subsistencia, campesinos-artesanos, campesinos-albañiles; artesanos, trabajadores que ya no pueden llamarse campesinos, pasando de obras de construcción a un taller, trabajando estacionalmente como jornaleros, desvinculados de la tierra, de la comarca y del ritmo de la agricultura de subsistencia; y mujeres, sobre todo campesinas-domésticas, campesinasartesanas, campesinas-vendedoras. Más de la mitad de estas personas, probablemente más de un $60 \%$, tenían menos de 30 años. De esta forma, las vendedoras de los mercados y de las calles hacían parte de estos flujos, pero a la vez se valían de ellos y de su concentración en San Salvador en busca de clientes potenciales.

De lo anterior, interesa dejar claro que estas mujeres venían más por una razón de tipo cultural y comercial, más que industrial, es decir, las vendedoras, como parte de los flujos migratorios se sentían atraídas a la ciudad debido a la concentración de población, al mercado potencial que ello significaba, más que por buscar un empleo en una industria ${ }^{26}$. La función industrial, tan debatida durante el periodo de bonanza de los años 1910 y 1920, y de nuevo en el centro de los debates más apasionados en los años 1940, fue marginal, por lo menos hasta 1948 a no ser que se incluyan las actividades artesanales múltiples.

\section{Una actividad mayoritariamente femenina}

26 Ver: Juan Mario Castellanos, “El Salvador 1930-1960”. San Salvador: DPI, 2001, pp. 138-140. 
El análisis de los artículos de La Tribuna permite concluir que las prácticas de las ventas en los espacios públicos y los mercados en El Salvador y, principalmente en San Salvador, estaban dominadas por mujeres. La frecuencia de las referencias femeninas, las categorías usadas, como los comentarios periodísticos respaldan esta afirmación.

Se afirma una presencia mayor de mujeres por el número de tipos femeninos. Así, al comparar la tipología femenina $(12 / 29,10 / 16,11 / 13$ y $10 / 17)$ a la masculina $(10 / 29,3 / 16,0 / 13$ y $3 / 17)$, se observa una sub representación de los tipos masculinos, resultando 353 frecuencias femeninas en un total de 426. Aún más se observa esa dominación femenina cuando se agrega una parte de los términos neutros que incluyen de manera segura a mujeres, para los diferentes períodos (tipos: $7 / 29 ; 3 / 16,2 / 13$ y $4 / 17$ ).

Al cruzar tipología y frecuencia, el término "locatarias" aparece en primer lugar con 151 frecuencias, "vendedoras" en segundo con 70, "señoras" en tercer lugar con 42 y "vendedoras ambulantes" con 26. A partir de esto se concluye, primero que se observa la presencia dominante de las mujeres. Segundo, era la práctica comercial sin referencia de otra índole, que caracterizaba a "las vendedoras". Tercero, el único termino de otro tipo es el de "señoras", el cual es una prueba de la relevancia de la relación de género en el abordaje de las "actividades de venta" en los mercados o en otros espacios públicos.

El análisis cualitativo, fundamentado en los comentarios periodísticos, confirma las conclusiones precedentes y da más precisión sobre la importancia numérica de las mujeres en "las ventas" en los mercados y en la calles. Así, un periodista alude a las vendedoras del Mercado Central de San Salvador como personas que "representan el sostén de miles de hogares capitalinos", evaluando a más de 1,200 vendedoras afectadas por una medida municipal ${ }^{27}$. De igual manera,

27 "Vendedoras del mercado están muy preocupadas: $\mathrm{Y}$ ayer se presentaron al ministerio para exponer su 
respecto a las vendedoras de los espacios públicos de la capital, otro artículo se refiere a "miles de vendedoras que ahora inundan las calles de la capital, hasta el grado de haber alterado el tránsito en muchas de ellas" ${ }^{” 28}$.

El análisis cuantitativo y cualitativo del diario confirma las conclusiones que se habían extraído del análisis de las 42 imágenes del catálogo de ventas en los espacios públicos de los pueblos y ciudades del país, entre 1890 y 1939, ya que en 33 de las 42 imágenes se observan mujeres vendedoras ${ }^{29}$.

Definitivamente, el centro de la ciudad se veía mucho más feminizado que otras partes. El análisis del censo de 1930 y de 1950 puede aportar una parte de la respuesta en torno de esta dominación espacial femenina. Según el censo de $1930^{30}$, mientras que la población total del casco urbano de la ciudad capitalina representaba 88.508 personas, 41.860 eran varones y 46.648 mujeres, lo que significa que casi un 53\% de las personas que radicaban en el centro eran mujeres. Podría ser el resultado de una migración campo-ciudad más fuerte de parte de las mujeres que de los hombres. En esta población que procedía del campo se podría encontrar a más empleadas de casa, vendedoras y obreras que a albañiles, artesanos, obreros o empleados.

\section{Una actividad precaria pero no marginal}

Si se retoma la tipología de los economistas de la informalidad, Rafael Menjívar Larín y Juan Pablo Pérez Sáinz, se observa que de las tres categorías propuestas - "lógicas de subsistencia en punto de vista", La Tribuna, 17 de agosto de 1944, Año I, No. 44, pp. 1 y 4.

28 "Negociantes que serán retirados del mercado. Gestiones para que se instale allí exclusivamente a locatarias. Personas pesimistas creen que surgirá allí nuevo problema”, La Tribuna, 2 de abril de 1946, Año II, No. 472 , pp. 1 y 4.

29 Olivier Prud'homme, Oscar Campos y Lorena Olmedo. Ob. Cit.

30 Rodolfo Barón Castro, La población de El Salvador. San Salvador: DPI, 2002, p. 445. 
reproducción simple", "situaciones a caballo entre la dinámica acumulativa y la reproducción simple de subsistencia" y "la dinámica acumulativa"-, solo se distinguen "las lógicas de subsistencia en reproducción simple" ${ }^{31}$. En 368 noticias, no se pudieron identificar otros perfiles sociales que el de subsistencia. Tampoco se pudo diferenciar la situación socio-económica de las vendedoras de las calles y de los mercados de El Salvador, principalmente de la capital.

Los ejemplos que aluden a la situación social de las vendedoras de los mercados y de las calles son numerosos, tales como "pobrecitas mujeres que se ganan el pan de sus hijos vendiendo frutas por la calle"32; o los "pequeños intereses de las humildes locatarias"33. Entre estas mujeres vendedoras, unas noticias aluden a la presencia de campesinas, "pobre gente del campo"34.

En el catálogo de imágenes de las ventas entre 1890 y 1939 se había percibido esta homogeneidad social de las vendedoras, casi todas vestidas de un fajo y de una camisa sencilla, confundiéndose con sus clientes, empleadas de casa.

En una situación precaria, a nivel social y económico las vendedoras hacían parte de la población, ya fuera rural o urbana. Eran parte de este $92 \%$ de la población que tenía un 48\% del producto nacional según una encuesta de las Naciones Unidas de 1951. Eran a la vez las proveedoras y una parte de esta categoría C, que describe el economista Héctor Dada Hirezi: que compuesta por el $61 \%$ de la población, recibe solamente el 19,5\% del ingreso total. Las capacidades de consumo que permite el ingreso medio de esta última categoría no pasa más allá de los bienes 31 Rafael Menjívar Larín y Juan Pablo Pérez Sáinz, Ni héroes ni villanas: Género e informalidad urbana en Centroamérica. Op. Cit., p. 16.

32 "Casos y cosas/Lo que se ve y lo que no se ve: Las carretillas fruteras", La Tribuna, 16 de agosto de 1944, Año I, No. 43, p. 3.

33 "Atropello a las señoras del mercado. El alcalde promete darles pronta ayuda", La Tribuna, 19 de febrero de 1946, Año II, No. 436, pp. 1 y 6.

34 "Situación anómala: retiran de una calle a unas vendedoras", La Tribuna, 18 de septiembre de 1944, Año I, No. 70, p. 1. 
no duraderos; es más, difícilmente alcanzan $\$ 58$ al año para cubrir las necesidades básicas de una persona $(\ldots)^{35}$.

Entonces estas mujeres eran informales en una sociedad en la cual la pauta era la precariedad y la informalidad, un tiempo vendedoras, otro, domésticas o costureras. Las mujeres vendedoras seguían trayectorias laborales muy inestables comparables a las de los hombres mencionados por el director del proyecto de Seguro Social en 1947: Este núcleo de población que clasifico como asalariados temporales puede aún dividirse en dos categorías. La primera estaría compuesta por aquellos trabajadores que se dedican a trabajos temporales en propiedades cercanas a su domicilio. Viven en un pueblo determinado ejerciendo alguna actividad especial en un pueblo y cuando hay demanda de trabajo en las fincas circunvecinas se convierte en asalariado temporal. La segunda categoría estaría formada por trabajadores que se encuentran en los centros de trabajo pero que viven en lugares distantes, viajan constantemente de un lugar a otro en busca de trabajo o de acuerdo con el ritmo de la producción agrícola ${ }^{36}$.

\section{Las vendedoras de los espacios públicos y de los mercados: principal aporte a la economía familiar}

Para terminar, el análisis de las noticias de La Tribuna permitió distinguir la importancia del papel económico de las vendedoras en la economía familiar.

35 Héctor Dada Hirézi, Ob. Cit., pp. 43-45. Por un artículo en la ECA se pudieron alcanzar los costos de la vida para un obrero probablemente de San Salvador en 1947: Un solo individuo consume diariamente, sin tener en cuenta los gastos supérfluos y ayuda a la familia, lo siguiente: por comida $\$ 1.20$, por alquiler de casa (en mesón) 0.35 , por calzado 0.20, por vestuario 0.20, por transporte al trabajo 0.12, por medicina, refrescos 0.20, por alumbrado de velas 0.05, por lavado de ropa 0.09, total: $\$ 2.41$. Agregaba: actualmente en El Salvador, y aproximadamente sucede lo mismo en los demás países del istmo, el peón gana solamente $\phi 1,50$, y el oficial o maestro $\phi 3$. S.J. Alfonso Ma. Landarech, "El salario: justicia o caridad", en $E C A$, no 8, marzo de 1947, pp. 9-10.

36 Francisco Roberto Lima, "El seguro social”, en $E C A$, n 12, julio de 1947, p. 6. 
Sin conocer el estado civil de las vendedoras, varias expresiones aluden al papel central de las vendedoras en la economía familiar: "proveedoras del pan de la familia" ${ }^{37}$, "pobrecitas mujeres que se ganan el pan de sus hijos"38; "actividades que son lícitas y que constituyen el único patrimonio para la subsistencia de las mismas vendedoras y sus hijos ${ }^{39}$ ". "representan el sostén de miles de hogares capitalinos” ${ }^{\prime 40}$ ¿Madres solteras? o ¿jefas de familia que aportaban la mayoría de los ingresos al hogar, en el caso que vivieran en pareja? Lo cierto es que las representaciones de estas vendedoras construyen una imagen de mujeres económicamente independientes, en la cual los hombres están totalmente ausentes. Sin escoger una de las dos interpretaciones acerca de la situación familiar de las vendedoras de los mercados y de las calles, el rol de las vendedoras en la economía familiar era central.

Su papel en la economía familiar se refuerza con el cuidado de los niños a cargo de las mujeres y es visible, como todavía hoy, en los espacios de venta. Así, en una noticia sobre un mercado, un periodista representó a “niños encanastados o rodando por el suelo, recibiendo la contaminación directa de todos los microbios disponibles", por lo cual se pedía la construcción de una sala infantil ${ }^{41}$. En otra noticia: $\square$ Todas las locatarias del mercado municipal No. 2 gozan de comodidad y de muchas ventajas, sobre todo, las señoras que tienen hijos recién nacidos, o niños pequeños, porque hay en el edificio sala cuna, escuela, un buen provisto botiquín y servicio de emergencia

37 "Acosan a funcionarios de la municipalidad: Mucha demanda de puestos para vender", La Tribuna, 13 de julio de 1944, Año I, No. 16, p. 1.

38 "Casos y cosas/Lo que se ve y lo que no se ve: Las carretillas fruteras", Op. Cit.

39 Contra alcalde presentan queja las vendedoras. Piden justicia a las altas autoridades”, La Tribuna, 9 de septiembre de 1945, Año II, No. 299, pp. 1 y 4.

$40 \quad$ "Vendedoras del mercado están muy preocupadas: Y ayer se presentaron al ministerio para exponer su punto de vista", $O b$. Cit.

41 "Sala cuna se necesita en un mercado. Magnífica sugerencia de la municipalidad", La Tribuna, 19 de febrero de 1946, Año II, No. 436, p. 1. 


\section{( ) $\square$.}

En una noticia más detallada, una locataria manifestaba que: "Se entiende que las locatarias somos gentes pobres, y que en tal concepto, no podemos pagar de una china para que cuide de nuestras criaturas. Por otra parte, nuestros hijos en edad escolar llegan a comer donde nosotros trabajamos, pues a causa de nuestra misma pobreza alquilamos piezas de los mesones alejados del centro de la ciudad (...) ¿Cómo vamos a dejar a nuestros hijos encerrados en las piezas en que habitamos? ¿Quién les daría de almorzar si en las horas del mediodía es cuando tenemos más trabajos"43.

Esta cita precisa otra característica de la economía de subsistencia de las vendedoras: el lugar de residencia, que confirma las conclusiones del apartado anterior sobre la precariedad de estas mujeres. De hecho, en 368 noticias sobre el tema de las ventas y de las vendedoras, no se hizo mención de otro tipo de lugar de residencia que las piezas de los mesones, los cuales eran de gran proliferación a finales de los años 30 e inicios de los cuarenta constituyéndose en lugares de residencia del proletariado urbano antiguo y del proletariado rural recién establecido, temporalmente o permanentemente, en la capital. Las vendedoras pertenecían al proletariado urbano y rural, ambos caracterizados por la pobreza y la precariedad.

Así, el centro no sólo tenía una función económica para una mayoría proletaria sino también una función residencial. Obviamente, antes de los años 1920, una gran parte vivía como domésticas en las mansiones burguesas del centro o en la periferia rural cercana dedicada al café o a un cultivo alimenticio. A partir de los últimos años de la década de 1910, con un testimonio de

42 "Hay espacio en el mercado número 2. Pueden trasladarse allí vendedoras callejeras", La Tribuna, $1^{\circ}$ de diciembre de 1948, p. 1.

43 “Agentes municipales no permitieron niños en unos mercados de la capital”, La Tribuna, 18 de mayo de 1946, Año II, No. 508, p. 1. 
Miguel Mármol, se tienen las primeras referencias de mesones populares en el centro ${ }^{44}$. Es más, las referencias se multiplican a partir de finales de 1920,1930 y hasta el periodo en estudio. Mario Lungo Uclés, Sonia Baires, América Rodríguez Herrera ${ }^{45}$ y tesis de graduados en arquitectura plantean el gran desarrollo de los mesones, sobre todo, a partir de los años 1930.

Entre 1944 y 1948, el tema era recurrente en periódicos como La Tribuna. A la par de la peligrosidad del tráfico automovilístico, de la ocupación de las calles por ventas en la ciudad, la cuestión de los mesones -símbolo de insalubridad en los discursos periodísticos y políticos- era una preocupación urbana muy mediatizada. En 1946, los encargados de llevar a cabo el proyecto del Seguro Social escribían: El problema de la vivienda es algo horripilante en las ciudades y en el campo. (...) y los fétidos, insalubres e inmorales mesones en que se amontan la mayor parte de nuestra población urbana, ¿mejoran la solución?46

A manera de conclusión, desde el análisis cualitativo, en la medida que disminuye el número de noticias sobre las ventas ambulantes y en las calles, disminuyen las informaciones del perfil social. Cuatro características aparecen con mayor frecuencia: el gran número de mujeres que se dedicaban a las ventas, su actividad como una economía de subsistencia, su aporte a la economía familiar y su papel de madres.

44 Hacia 1917, “Comerciantes hondureños venían a San Salvador a traer zapatos y se quedaban en los mesones que al efecto empezaron a levantarse, precisamente en la entrada de la ciudad, después de la garita de San Sebastián y en los terrenos que ya se identificaban como el barrio de Concepción, en la $\square$ plazuela de Ayala $\square$ y que eran también habitación de los primeros inmigrantes pobres que llegaban a la ciudad a buscar trabajo. Entre ellos hubo mujeres que se ocupaban en la elaboración de tortillas, y posiblemente también en el servicio doméstico. $\square$ Flora Leticia I. Salazar Ledesma, Ob.Cit., p. 99.

45 América Rodríguez da el ejemplo de los mesones del barrio San Esteban en los años treinta. América Rodríguez, San Salvador: Historia urbana (1900-1940), San Salvador: DPI, 2002, p. 56.

46 Salvador Martínez Lovo y Francisco R. Lima, "Sobre el departamento de trabajo”, en ECA, mayo-junio de 1946, p. 12. 
Las mujeres que trabajaban en el comercio ambulante o en el mercado eran representadas por los periodistas de La Tribuna, a partir de su oficio. Estas "señoras", fueran "locatarias" o “ambulantes", practicaban un comercio que participaba de una lógica de subsistencia, en la cual su aporte a la economía familiar era muy importante por ser el sostén de la familia -carente de un aporte masculino relevante- y por cargar con la responsabilidad del cuido de los niños. Mientras tanto, los silencios periodísticos no permiten conocer otros aspectos importantes del perfil social, como la edad, el estado civil, la residencia, la procedencia y la educación.

\section{Conclusión}

Siguiendo el enfoque de la historia de las mujeres, también hay que explicar los silencios de los periodistas, los cuales eran varios, entre estos: la edad, el estado civil, la residencia, la procedencia, la educación. Como se ha concluido del análisis cualitativo del perfil social de las vendedoras, hay indicios acerca de que estas mujeres eran jefas de hogar que aportaban la mayoría y probablemente los únicos ingresos, lo que se refuerza con el hecho que fueran las encargadas de cuidar los niños. Muchas veces se lee que eran las encargadas de proveer a la familia y de ganar el alimento de sus hijos. Con seguridad, se puede decir que estas mujeres eran independientes en lo económico, ámbito en que los hombres estaban ausentes. Esto afirma su rol fundamental en la economía familiar. Por ende, en este artículo, a pesar de que se comparte el análisis de Thomas Anderson sobre la precariedad, factor de movilidad laboral y de inestabilidad familiar en los años treinta y que se puede extender a los años cuarenta, no se puede apoyar su conclusión sobre las relaciones entre estos hombres y mujeres que conformaban la mayoría de la población salvadoreña:

(...) Una explicación obvia la proporciona el estilo de vida de la gente pobre del país. Teniendo 
en cuenta las condiciones de vida marginal del trabajador rural, la frecuente necesidad de "elevar anclas" para trasladarse de una parte a otra del país, y el costo agregado que por lo general significa vivir con mujer e hijos, no es nada sorprendente que, en muchas ocasiones, el hombre que se ve forzado a ir de un lugar a otro en busca de trabajo tome a la mujer que encuentre más a mano. Viva con ella por un tiempo, le ayuda a sostener a todos los niños que pueda haber tenido de previos visitantes, y luego, cuando el patrono se pone muy pesado o pasa la cosecha de café, sigue su camino. La mujer, cargada con una prole cada vez mayor, se queda en el lugar, esperando el paso de otro trabajador que se interese por ofrecerle una ayuda temporal ${ }^{47}$.

Se considera que su análisis da énfasis a la movilidad masculina y descarta el trabajo femenino móvil. El ejemplo de las vendedoras de San Salvador demuestra que las mujeres alimentaban también los flujos hacia la capital, y por ende eran móviles. Segundo, la última frase del párrafo citado presenta a las mujeres pobres como totalmente dependientes de los hombres: "esperando el paso de otro trabajador que se interese por ofrecerle una ayuda temporal". Invisibiliza el trabajo femenino, como el de las vendedoras, quienes, probablemente, trabajaban a diario, con jornadas muy largas y con sus hijos a la par, sin esperar a un hombre que llegara temporalmente para mantenerlas.

Un editorial de La Tribuna confirma de manera magistral la interpretación defendida en esta tesis: (las mujeres) las vemos en las oficinas de gobierno, en las escuelas, en los bancos, en los almacenes y en los mercados. (...) una de las ocupaciones que más atraen a las mujeres son las ventas en las calles. San Salvador y otras ciudades de población densa exhiben en sus lugares céntricos una multitud de vendedoras de frutas, pan, dulces, trajes ya confeccionados y objetos de achinería ${ }^{48}$.

47 Thomas R. Anderson, El Salvador 1932. San Salvador: DPI, 2001, p. 84.

48 "Editorial: Las ventas callejeras", La Tribuna, 20 de octubre de 1948, p. 3. 